\title{
Anomia y crisis social en el Perú del bicentenario
}

\author{
Recibido: 08/02/2021 \\ Aprobado: 28/06/2021 \\ Publicado: 31/07/2021
}

\author{
Aaron CAYCHO CAJA \\ Universidad Nacional Federico Villareal (UNFV) \\ Universidad Peruana del Norte (UPN) \\ aaronkaycho@gmail.com \\ https://orcid.org/0000-0003-1478-8954
}

\section{RESUMEN}

La crisis social provocada por la pandemia del SARS-CoV-2 viene a acelerar condiciones preexistentes en la sociedad e impone cambios estructurales rápidos. En ese contexto, se describe la anomia como un fenómeno adyacente a la pandemia y visible en la ausencia de normas que regulan las pautas sociales. El objetivo del presente artículo es identificar las circunstancias previas a la aparición de la anomia en un contexto político ligado a la corrupción de los cinco últimos años. Luego, se destacan las características que permiten distinguir la anomia social en el contexto de la crisis actual. Posteriormente, se señalan sus implicancias en el sector laboral y cómo esta se manifestó en la participación de la sociedad civil en las marchas del año anterior. Asimismo, se explica, desde la psicología, la anomia individual en su sentido subjetivo. El ensayo culmina planteando la posibilidad de reorganización social, bajo las condiciones actuales de incertidumbre social.

Palabras clave: anomia, pandemia, política, crisis social

\section{Anomie and social crisis in Peru of the bicentennial}

\begin{abstract}
The social crisis caused by the SARS-CoV-2 pandemic has accelerated the pre-existing conditions in the society and enforces quick structural changes. In this context, anomie is described as a phenomenon adjacent to the pandemic and visible in the absence of norms that regulate social patterns. The aim of the present paper is to identify the circumstances preceding the emergence of the anomie in a political context stirred by the last 5 years of corruption. Moreover, we underline the characteristics that allow us to distinguish social anomie in the context of the current crisis. Subsequently, we point out its implications in the labor sector and how it manifested itself in the participation of civil society in the marches of the previous year. In addition, the subjective sense of the individual anomie is explained from a psychological point of view. The essay concludes by suggesting the possibility of social reorganization under the current conditions of social uncertainty.
\end{abstract}

Keywords: anomie, pandemic, politics, social crisis 
I a pandemia ocasionada por el SARS-CoV-2 es uno de aquellos acontecimientos significativos en el curso de la historia que será recordado como el punto de quiebre del paso definitivo del siglo XX al XXI, ya que su efecto viene provocando una profunda aceleración de las críticas condiciones económicas, sociales y políticas preexistentes, las cuales, incluso en la actualidad, avizoran cambios radicales en los cimientos de la sociedad tal y como se la conoció en el siglo anterior. Esta crisis estructural originada de manera abrupta también implica una nueva imposición cultural a nivel de la subjetividad individual, ya que obliga a las personas a adquirir nuevas pautas laborales, sociales y recreativas, y a dejar de lado los patrones tradicionalmente empleados.

En el Perú, la pandemia tuvo un inicio lejanamente amenazador, pero en pocas semanas evidenció sorpresivamente su radio de alcance. De pronto, la ciudadanía comenzó a ser testigo del caos inicial: aún se recuerda la desesperación de la gente por agenciarse de los productos básicos de primera necesidad y fue evidente la fragilidad del sistema estatal para asegurar el orden de un país de más de 30 millones de habitantes. Siguió un período de confinamiento obligatorio ordenado al inicio de la pandemia, lo que con el correr del tiempo terminó perjudicando la actividad laboral de muchos ciudadanos, causando de manera progresiva un descontento generalizado y la urgencia de conseguir recursos económicos para aquellas personas que no contaban con los medios necesarios para su subsistencia. La ola de malestar e incertidumbre se hizo masiva en los hogares y el desorden fue más que evidente en las aglomeraciones públicas, contrarias a la exigencia del cumplimiento de las medidas de protección sanitaria. A esto se añadió una pugna política entre el Poder Legislativo y Ejecutivo, que llevó a la inestabilidad del Estado y a la subsiguiente destitución del expresidente Martín Vizcarra, con un alto porcentaje de aprobación ciudadana, pero acusado de corrupción. Finalmente, fue separado del cargo por el Congreso de la República al alegarse su incapacidad moral. No obstante, ante el ascenso al mando presidencial del impopular Manuel Merino, las protestas sociales mostraron el descontento de la población y terminaron por obligarlo a renunciar, llevando a Francisco Sagasti a asumir el cargo como nuevo mandatario. Además, como una ola sucesiva de protestas sociales en Latinoamérica, aparecieron nuevos reclamos con distintos requerimientos en diferentes puntos del país, lo cual ha ocasionado una inestabilidad social más que evidente y con pronóstico desalentador. 
Frente a eso, el Estado exhibe su ausencia de liderazgo, organización y acusa su propia incapacidad para operar de acuerdo con las normas jurídicas que la sustentan, las cuales se acomodan en torno a los vaivenes de las decisiones no consensuadas de las agrupaciones políticas. En otro frente, la sociedad civil muestra que el país necesita, de manera urgente, poner en práctica las normas básicas de ciudadanía, ya que aún es evidente la falta de compromiso para asumir roles que permitan la convivencia social en situaciones críticas. A lo anterior se añade la inestabilidad social que se manifiesta en el individuo y lo coloca en una posición de incertidumbre ante la avalancha de cambios a los que se enfrenta y a los cuales difícilmente se va acostumbrando.

Un escenario de este tipo puede ser explicado en términos del pasaje bíblico del Apocalipsis. En este se relata la aparición de cuatro jinetes: uno de ellos monta un caballo negro que augura la hambruna; sigue a este uno rojo que presagia la guerra entre las naciones; el jinete de corcel pálido anuncia la peste; y el cuarto, alusivo al mesías bíblico, monta un caballo blanco y se le asigna una corona para vencer.

Cada uno de estos hace referencia a lo que sucede en el país. En una atmósfera apocalíptica, se tiene la amenaza latente de la catástrofe económica alimentada por el constante amedrentamiento de los medios de comunicación que alertan de los peligros de convertir el país en una economía socialista que lleve al descalabro y la consiguiente falta de alimentos. Se añade la constante polarización social que está a punto de estallar en conflictos internos de gran escala, azuzados por líderes políticos que aún siguen llamando terroristas a aquellos que van en contra de sus intereses. Como si no fuera poco, se anuncia una tercera ola que incrementaría la cifra oficial de 190 mil muertos por la pandemia y el posterior desborde sanitario. Frente a esto, se encuentra la fe religiosa, obnubilada y mesiánica en que aparecerá un líder, quizás se extraña un dictador, que sacará rápidamente al país de esta crisis porque no hay mal que dure cien años.

A ellos se añade un quinto jinete acéfalo, que no implanta el caos social ni institucionaliza el orden, pero impone un clima de incertidumbre constante a nivel del individuo que desconoce su estabilidad económica, familiar o su futuro laboral y a nivel de las instituciones desprestigiadas como el Poder Judicial, Ministerio del Interior, Congreso de la República o la propia Presidencia de la República, las cuales se han caracterizado por los vaivenes constantes en sus decisiones. Es un quinto jinete anómico que mantiene un clima de turbulencia constante en la misma estructura social, y que genera 
una transgresión institucionalizada a las normas sociales que rigen las conductas de los individuos que no respetan la convivencia ciudadana, lo que se evidencia en el funcionamiento de las instituciones estatales que utilizan la burocracia y la interpretación de las leyes con fines políticos, y se plasma en la sociedad civil que luce acéfala y desarticulada, con un sinfín de protestas que no convergen en una organización definida de líderes que canalicen las verdaderas demandas de la ciudadanía. A pesar de este panorama sombrío, la anomia también apertura una posibilidad de cambio, quizás remota, de reorganización social que coincide con una fecha simbólica asociada al bicentenario de la república.

Según lo mencionado, aparece como interrogante si los fenómenos sociales originados por el desborde provocado por la pandemia originada en el año 2020 evidencian la anomia y la crisis social en el país. En ese sentido, el presente ensayo describe las condiciones asociadas al fenómeno anómico y se señala sus características principales en el marco de la crisis actual. Como es necesario enfocar un fenómeno social que, al mismo tiempo, se expresa en la subjetividad del individuo, el análisis sigue la propuesta sociológica del funcionalismo estructural de Parsons y Merton, pero enfatizando el sentido psicológico de la anomia señalado por este último. De acuerdo con esto, se hace mención a la forma en cómo esta se manifiesta en el sistema político, social, cultural, educativo, además de brindar un análisis psicosociológico de su efecto a nivel de la subjetividad del individuo. Finalmente, se culmina con una mirada a la posibilidad del cambio y reorganización social a partir de la anomia social descrita.

\section{Breve reseña sobre el debate en torno a la anomia en el Perú}

En la década del ochenta se dio un intenso debate teórico sobre la naturaleza anómica de los fenómenos sociales acaecidos en los años anteriores. La discusión tomó como punto de partida el impacto de la migración del campo a la ciudad generado entre las décadas de los años sesenta y ochenta. En ese contexto, Hugo Neira (1987) argüía que este tenía una connotación negativa, porque rompía con la pauta moral tradicional de la sociedad limeña e imponía el desorden provocado por la orfandad cultural de los migrantes que no mantenían la moral de la aldea andina y tampoco asimilaban "la urbanidad de los viejos limeños”. Contrario a este, Nicolás Lynch (1989) colocaba sus 
esperanzas en el proceso migratorio, considerando "la posibilidad de desarrollo alternativo" y con esto la integración social del país. Posteriormente, al involucrar la anomia a fenómenos de múltiple complejidad, algunos autores (Carrillo y Sulmont 1991) también han brindado aportes con la intención de esclarecer los conceptos empleados por Neira y Lynch.

En las décadas siguientes, la inestabilidad social idiosincrática del Perú se ha seguido estudiando desde el enfoque teórico de la anomia a partir de la orientación sociológica de Durkheim, Parsons y Merton. En el caso de la psicología, bajo el camino señalado por Robert Merton (1964), se ha vuelto a poner en uso el concepto de anomia desde su concepción psicológica o subjetiva. Psicólogos sociales como Jorge Yamamoto (2020) identifican en ella un problema asociado a la dificultad para el cumplimiento de las normas básicas de convivencia y respeto a los demás en los diferentes estratos sociales del país. Desde la psicometría, con un especial énfasis de otorgar un mayor grado de precisión al uso de la definición operacional de los constructos sociales a través de análisis estadísticos rigurosos, como el modelamiento por ecuaciones estructurales, se ha realizado aportes al estudio de la anomia desde la validación de escalas psicométricas adaptadas para su uso exclusivo en población peruana, a la vez que se ha brindado algunas características empíricas de esta (Caycho 2019, Caycho 2020).

A pesar de que la anomia posee una larga tradición en las ciencias sociales, es un concepto fértil para explicar la irrupción de los fenómenos descritos por Neira y Lynch como los acaecidos en los años ochenta en el Perú, al igual que los eventos sucedidos en Estados Unidos a mitad del siglo XX, o aquellos señalados por Durkheim en Europa a inicios del siglo anterior. De la misma manera, su uso vuelve a hacerse necesario en un contexto de crisis social y cambios estructurales vertiginosos en el siglo XXI.

\section{Los antecedentes a la pandemia: anomia en la política y el Estado}

Era de esperar que un acontecimiento mundial como la pandemia del 2020 ocasionara fuertes repercusiones sociales, incluso en aquellos países que gozan de mayor estabilidad y desarrollo que el Perú. Sin embargo, las consecuencias que se experimentan no son obra exclusiva de la pandemia, sino que ya se avizoraban ciertas condiciones que alertaban sobre estas. De acuerdo con lo señalado, se menciona que el Perú es uno de los países con mayor ines- 
tabilidad política en los últimos cinco años (Paredes y Encinas 2020); además, desde inicios del siglo, todos los presidentes del país se han visto envueltos en acusaciones de corrupción, algunos de ellos han estado en la cárcel, y uno de ellos se suicidó al sentirse acorralado por la justicia. Asimismo, antes de la llegada de la pandemia, las instituciones representativas del Estado como el Poder Judicial han estado involucradas en casos de corrupción como el de los Cuellos Blancos del Puerto, lo cual ha llevado a magistrados "reputados" a la cárcel (Ministerio de Justicia y Derechos Humanos 2019). Se puede añadir que las municipalidades también se han visto envueltas en este tipo de acusaciones, e incluso dos exalcaldes de Lima Metropolitana como Susana Villarán y Luis Castañeda se encuentran sentenciados o cumpliendo prisión preventiva por actos de asociación ilícita para delinquir.

Es importante destacar que Perú, el otrora "tigre de Sudamérica" (Chirinos 2008), no ha podido plasmar su crecimiento económico de los años 20052015 en desarrollo social en el país. De hecho, ha mostrado serias dificultades para mejorar la infraestructura en sectores vitales como el sanitario. Se enfatiza que, a pesar de la defensa del modelo económico peruano de crecimiento, este tampoco se ha traducido en mejoras sustanciales para la población, lo cual se ha hecho evidente en la inversión por debajo del promedio en el gasto público en salud a comparación de otros países latinoamericanos (BBC 2020) y en la respuesta ineficiente al desborde sanitario provocado por la pandemia. Esta responsabilidad es consecuencia de las políticas de salud respaldadas por el Estado en las últimas décadas y se ponen en evidencia en la presente crisis social.

La situación se puede hacer mucho más problemática si se recuerda la escasa capacidad resolutiva de conflictos sociales por parte del Estado; sobre todo aquellos de tipo socioambiental, ligados a la actividad hidrocarburífera o minera. Anteriormente ya se ha visto cómo el Estado tiene una dificultad evidente en gestionar los conflictos sociales relacionados a la extracción de materia prima en condiciones beneficiosas para el sector privado y, especialmente, los sectores sociales disconformes. En febrero del 2020, antes de las medidas restrictivas sanitarias, el país contaba con 188 conflictos sociales registrados en diversas zonas del país; para agosto, de los 190 registrados, 127 correspondieron a conflictos socioambientales activos y latentes, de los cuales 70 estuvieron relacionados con la extracción minera y 23, con actividades hidrocarburíferas (Defensoría del Pueblo 2020). Bajo este contexto, si se considera que muchos de los conflictos sociales registrados aún no han sido resueltos y 
el descontento de los sectores sociales involucrados se agudiza bajo las condiciones desfavorables provocadas por la pandemia, existe una peligrosa posibilidad de que el estallido social sumerja al país en el caos y conlleve a saldos fatídicos, como los acaecidos anteriormente. Añádase a los mencionados, la diversidad de demandas sociales pendientes de distintos sectores sociales que se han visto perjudicados por años de abandono del Estado y cuyas precarias condiciones se han incrementado a causa de la actual crisis: bajo las condiciones actuales, es muy probable que ahora se vean en la imperiosa necesidad de buscar soluciones precipitadas a sus demandas.

\section{Contextualización de la anomia actual}

\subsection{Anomia social}

Emile Durkheim (1965 [1897]) decía que, al aparecer períodos de transiciones bruscas, las normas sociales y las pautas culturales tradicionales cambiaban de tal forma que las personas se veían influenciadas por la naturaleza de estos acontecimientos. Si bien siempre se han dado cambios de este tipo, las transformaciones han sido más rápidas en los últimos tres siglos debido a la industrialización de la sociedad y la apertura de los mercados (Durkheim 2012 [1893]). En este contexto, una persona que ha crecido bajo un sistema de valores relativamente definido se ve expuesta a la aparición de nuevas reglas que pueden ser diferentes o incluso contrarias a las tradicionales. En tales condiciones surge la anomia, entendida como un sentimiento subjetivo en el cual las normas adquiridas dejan de ser una pauta firme y las expectativas sociales sugieren nuevas normas implícitas u otras que pueden hacer confusas las anteriores. En todo caso, se hace permisible social e individualmente, en ocasiones necesario, el no seguir las pautas tradicionales y la adherencia tácita a las recientes variantes culturales.

La anomia, en su connotación sociológica, hace referencia a una condición objetiva expresada en la ausencia de normas que regulen las estructuras sociales y su funcionamiento de acuerdo con sus roles institucionalizados. Emile Durkheim (1965 [1897]) lo explica mediante las consecuencias que generaron las variaciones demográficas de Europa del siglo XIX, los procesos de migración a los centros urbanos, la aceleración de la industrialización y la posibilidad mercantil de generar una empresa global sin la necesidad de que 
estas conozcan sus propias sucursales. En Estados Unidos, Talcott Parsons (1966), en la década del sesenta, adscribe la anomia al sistema cultural, ya que genera nuevas pautas de interacción y expectativa social, pero coloca en desuso el mantenimiento de las condiciones culturales anteriores. Para Robert Merton (1964), las condiciones acusadas por Parsons llevan al establecimiento de metas sociales altas ("el sueño americano"), pero con sujetos que no disponen de los medios de acceso a ellas. Tales fenómenos son similares a lo acontecido en el Perú a causa de la migración interna del campo a la ciudad que generó una serie de conflictos sociales en décadas pasadas (Lynch 1989, Neira 1986).

Dadas las características señaladas, es necesario establecer analogías entre los fenómenos sociales denominados como anomia social y la serie de eventos vigentes en la realidad peruana. Para eso se describe el problema actual y las condiciones que posibilitaron su aparición, de tal forma que se pueda establecer un diagnóstico preciso del objeto en cuestión.

Se postula la presencia de la anomia social porque la crisis provocada por el SARS-CoV-2 ha mostrado cómo aún le cuesta a la sociedad poner en uso las normas básicas de respeto al "prójimo", lo cual se ha expresado en faltas jurídicas e injustificables a las cuarentenas decretadas. Esto revela una incapacidad social para originar mecanismos comunitarios de afronte de un problema sanitario y muestra la dificultad para generar pautas de conducta grupal de organización social en espacios públicos como mercados, centros comerciales, transporte público, todo lo anterior evidenciado en las aglomeraciones frecuentes observadas en estos lugares. Aquello está directamente asociado a una pauta cultural preexistente en el país que ha procurado brindar normas de convivencia social y ciudadanía, pero ante la imposición de la crisis actual, luce caduca e inoperante, ya que muestra cómo los pocos individuos que se suman a la adquisición de las nuevas pautas sanitarias o sociales son insuficientes para considerar un cambio medular en la conducta social del peruano promedio.

Además, en períodos de crisis el Estado tiene un rol más que importante, pero esto depende de las funciones que asuma en la sociedad. Así se tiene que en los países orientales el Estado tiene una mayor presencia evidenciada en el vigor de su poder infraestructural a diferencia de los países occidentales, quizás a causa de su tradición cultural estatista y autoritaria (Merino 2020). En el Perú las cosas son muy diferentes, debido a que el Estado y sus instituciones se han visto desbordadas por la pandemia y este ha mostrado 
su incongruencia para hacerle frente. Se señala, por ejemplo, que, frente al impacto económico originado por la cuarentena iniciada en el mes de marzo del año anterior, el Estado brindó de manera tardía e insuficiente un subsidio monetario para aquellas familias que paralizaron sus actividades económicas; sin embargo, no se desarrolló la infraestructura adecuada para que estos recursos lleguen a los más necesitados. La entrega de los bonos generó aglomeraciones masivas que probablemente fueron focos de propagación del virus y los padrones empleados se encontraban desactualizados, involucrando riesgos de corrupción en su distribución, entre otros problemas (Defensoría del Pueblo 2020b). Otras medidas como la entrega de víveres para paliar la cuarentena obligatoria resultaron irrisorios e iban acompañados de acusaciones de sobrevaloración de las canastas, bolsas de víveres incompletas, baja y lenta ejecución del presupuesto destinado por el Estado a los municipios (Ojo Público 2020), además de una dificultad evidente para llegar a las zonas periféricas de Lima, peor aún en provincias (Defensoría del Pueblo 2020b). Asimismo, el Ministerio del Interior, a pesar de los esfuerzos realizados, se ha visto desbordado en su capacidad de asegurar el orden público en el contexto sanitario actual, lo cual se pudo observar en las dificultades de los elementos policiales para hacer efectivo el cumplimiento de los protocolos establecidos para intervenir en casos flagrantes de falta a las restricciones; $y$, en muchos casos, se ha tenido más que una percepción de violencia y autoritarismo por parte de ellos. A esto se le suma el desborde en los hospitales, el problema de la educación, la economía, la informalidad y la precariedad del trabajo; cada uno de estos son temas extensos en su complejidad como para ser abordados a detalle en el presente escrito.

Si bien ya suficiente se tenía con la problemática descrita, los líderes políticos estaban enfrascados en una interminable pugna entre el Poder Ejecutivo y Legislativo que desembocó en una de las marchas más numerosas contra la asunción a la presidencia por Manuel Merino. Esto culminó en un estallido social, con la lamentable pérdida de dos jóvenes muertos que hacen recordar los días infaustos de la dictadura fujimorista respaldada por la represión autoritaria del Ministerio del Interior y las Fuerzas Armadas.

La crisis política actual ha influido notablemente en la forma en cómo los ciudadanos perciben las pugnas, acusaciones, demandas y demás singularidades de la clase política actual, pero también pone en evidencia su carácter contradictorio. En ese sentido, se ha visto la posibilidad de que un líder político, en este caso el expresidente Martín Vizcarra, a pesar de tener denuncias 
e investigaciones por casos de corrupción, se vea favorecido por el respaldo popular por el hecho de mantener una idealizada estabilidad política o, en una actitud oposicionista, posiblemente por darle la espalda a un Congreso de la República poco representativo y con una tasa de desaprobación alta. Resulta inquietante y peligroso que, en los períodos de cuarentena, se ha exigido un Estado con mayor presencia autoritativa, o posiblemente haya una actitud latente a favor de un Estado y un líder autoritario.

\subsection{Anomia y trabajo}

Para Emile Durkheim (2012 [1893]), la especialización laboral generada entre los siglos XIX y XX llevó a una división social del trabajo que fue útil al desarrollo de las sociedades europeas. Lo anterior también fue un desencadenante de los acontecimientos sociales a los cuales se enfrentó Europa en el siglo XX. De manera análoga, en el presente siglo, en una situación en la cual cambios vertiginosos se suceden uno tras otro, el análisis de las condiciones actuales del trabajo generadas por la pandemia posee no menor importancia, porque permiten describir y predecir los eventos posteriores.

En el caso peruano, el sector laboral se encuentra en una situación alarmante a causa de las cuarentenas y estados de emergencia decretados frente a la crisis sanitaria. Asimismo, tanto el sector privado como el estatal se han visto afectados, ya que se ha tenido que recurrir al empleo de medidas económicas o políticas laborales dirigidas a proteger la empresa privada o, en el segundo caso, a la postergación de diversos programas sociales, ambas decisiones con un costo social preocupante.

No obstante, la inestabilidad política de los tres sucesivos Gobiernos desde marzo del año anterior también ha influenciado de manera directa o indirecta en el sector laboral. Si bien muchos programas estatales se mantienen, las continuas interrupciones y cambios en el gabinete de ministros impiden generar políticas a largo plazo y se limitan a la atención de objetivos inmediatistas. A esto se añade que la inestabilidad en los líderes de los ministerios termina afectando a los cargos menores que, frente a los cambios de ministros, observan cómo los cargos de confianza en los cuales se encuentran diversas jefaturas se hallan en una situación incierta, lo cual ocasiona incertidumbre laboral. En esta situación es menos probable que los trabajadores se arriesguen a presentar proyectos a largo plazo beneficiosos, sino que busquen cumplir con proyectos paliativos que les permitan alcanzar las metas de los planes 
operativos anuales planificados, pero que a larga escala pueden estar manteniendo estructuras burocráticas improductivas o lejanas de la realidad.

A esto se le añade que, en el sector estatal, la inestabilidad laboral ya ha sido motivo de protesta a causa de contratos administrativos de servicios (CAS) o contratos de servicios por terceros en los cuales la relación laboral termina cada dos o tres meses, aproximadamente, y cuya renovación está sujeta a evaluación. En el caso del sector sanitario, muchas de sus demandas se han visto aplazadas en más de una ocasión, lo cual ha llevado a la amenaza de huelgas y paros masivos (Gestión 2020), justo cuando se necesita mayor personal para la atención en los diferentes establecimientos de salud colapsados por la cantidad de casos de SARS-CoV-2.

En cuanto al sector privado, muchos de los trabajadores se han sentido en la obligación de adaptarse a las nuevas condiciones impuestas; sin embargo, la informalidad y precariedad en la cual se han encontrado inmersos ha hecho que muchos de ellos se hayan visto impelidos a participar de protestas con saldos fatídicos como las sucedidas en Ica, al sur de la capital, contra la Ley N. ${ }^{\circ} 27360$, "Ley Chlimper", la cual beneficiaba largamente a las empresas exportadoras, pero mantenía en sueldos irrisorios a sus trabajadores. A estas condiciones se añade el riesgo permanente de reducción de personal, aspecto que modifica notoriamente la relación entre el empleado y el empleador.

Añádase que en el caso de los trabajadores informales la situación laboral es dramática, pero muchos medios de comunicación intentan romantizar esto de tal manera que el trabajador precario e informal pasa a denominarse a sí mismo como "emprendedor", y el desempleado que intenta generar los mínimos ingresos llama a su actividad "reinvención". Lamentablemente, es esta precariedad laboral uno de los elementos que ha ocasionado que la economía del país se haya visto tan afectada por la pandemia, ya que se estima que un $63 \%$ de los trabajos urbanos, de cinco regiones con alto contagio de SARSCoV-2, se caracterizan por su informalidad (Instituto Peruano de Economía 2020). Esto obviamente, ante la ausencia de oportunidades, generará una serie de problemas sociales posteriores.

En resumen, el ámbito laboral se ha visto largamente desbordado a causa de la pandemia y por las condiciones preexistentes a esta. Su efecto ocasiona inestabilidad en el sector más importante de la micro y macroeconomía, lo cual ya de por sí alerta de su influencia en aspectos que van más allá de las percepciones subjetivas individuales y se transforma en una condición objetiva real. No obstante, los proyectos futuros dependen, en su gran mayoría, de 
la confianza o seguridad de los individuos respecto a la posibilidad de producir lo suficiente para alcanzar sus metas personales o familiares. Sin embargo, bajo un clima de inestabilidad social, estos también verán mermada su autoconfianza para aventurarse a generar soluciones concretas a sus demandas.

\subsection{Anomia de la sociedad civil: las marchas acéfalas}

Un descontento canalizado en una actitud negativa hacia la clase política del país se hizo evidente a través de diversas marchas y protestas contra los líderes políticos, y en especial contra el Congreso y el ascenso a la presidencia de Manuel Merino en noviembre del 2020. Lo paradójico de las marchas en contra del Congreso es que este fue un Parlamento elegido de manera democrática por la misma ciudadanía ante el cierre del Congreso anterior, por Martín Vizcarra, en el 2019. No obstante, si bien las marchas expresaban la negativa de la ciudadanía a las pretensiones de diversos partidos políticos representativos del Parlamento, estas manifestaciones lejanamente promovían algún tipo de agenda propositiva, aunque, de manera poco enfática, se pedía un cambio de Constitución. Para respaldar esta afirmación, se puede decir que no existe algún partido político o agrupación que lidere el descontento generalizado y lo canalice a través de líderes que puedan plasmar por una vía democrática las demandas de la sociedad civil. Frente a la ausencia de líderes, fueron, en su mayoría, jóvenes y estudiantes de diversos sectores sociales los que salieron a protestar contra un Congreso tildado de obstruccionista; sin embargo, a pesar de que estas movilizaciones han sido realizadas con mediana o escasa organización, no llegaron a converger en un liderazgo claro o establecido que proponga una meta determinada. Incluso se podría decir que fue una protesta bienintencionada, que resultó en un retroceso a las condiciones previas a la destitución de Manuel Merino, si acaso tales condiciones fueron a extrañarse.

Luego, posteriores movilizaciones con diferentes pedidos se han venido dando sobre todo en provincias; no obstante, al parecer tales casos no gozan de la misma capacidad mediática que posee la capital o, en todo caso, no cuentan con el respaldo de las diversas organizaciones existentes para generar un eco masivo a las protestas. Si bien existen variados intereses en las diversas organizaciones sociales, es evidente la ausencia de liderazgo y articulación entre ellas. Esto muestra, por una parte, que la ciudadanía mantiene aún su capacidad de indignación y su insatisfacción ante las condiciones actuales, 
pero también pone en evidencia la ausencia de metas planificadas producto de una articulación entre diversos sectores de la sociedad civil.

¿Por qué los diversos acontecimientos sociales demoran en converger en una protesta organizada de la sociedad civil? Es muy probable que el autoritarismo del Gobierno de Fujimori, entre los años 1990-2000, haya tenido un efecto adverso en las diversas organizaciones representativas de la sociedad. Solo para recordar, fue en este período en el cual se acusó serias violaciones contra los derechos humanos de muchas personas contrarias al Gobierno de turno, las cuales al ser catalogadas como terroristas entraban en la categoría de enemigos del Estado, lo cual justificaba una violenta intervención (Burt 2000). Como consecuencia, la sociedad civil fue desmembrada y desarticulada desde sus bases a causa de la amenaza latente de la violencia política en contra de sus líderes comunitarios, las agrupaciones representativas y la organización de estas. Aquella generación que fue sometida a la represión es la que ahora es permisiva con la corrupción ("roba, pero hace obras") y muestra una actitud oposicionista hacia el involucramiento en la política; no obstante, los hijos y nietos de esta generación, que no han crecido con la violencia política, son los que han salido a protestar, muestran mayor interés en la vida política del país y, probablemente, vayan aprendiendo a organizarse.

\subsection{Políticas educativas estatales y la pugna con la Iglesia católica}

El Ministerio de Educación ha propuesto a través del Currículo de Educación Básica el enfoque transversal de igualdad de género con la finalidad de brindar un trato justo a las personas, independientemente de si estas son varones o mujeres. Tal enfoque supone una propuesta inclusiva que permite educar a los futuros ciudadanos de tal forma que sean capaces de reconocerse entre sí los mismos derechos y deberes. No obstante, ha generado la protesta airada de diversas agrupaciones eclesiásticas, las cuales señalan que este vulnera la concepción tradicional de la familia.

No es novedoso observar que muchas de estas agrupaciones cuentan con el respaldo del Opus Dei, al cual Francisco Durand relaciona de manera íntima con la familia Romero (Sánchez y Paredes 2010), dueña de las principales corporaciones del país. Este conglomerado de empresas generalmente se ha visto relacionado a la política, incluso el mismo Dionisio Romero Paoletti confesó haber brindado más de tres millones de soles para la campaña de Keiko Fujimori en el 2011. En ese contexto, es comprensible que la tres veces 
candidata a la presidencia muestre un marcado apoyo al movimiento Con Mis Hijos No Te Metas, en un afán de seguir en la misma línea ideológica que su colaborador.

El problema radica en que tales agrupaciones religiosas suelen ser dogmáticas y cercanas al fanatismo. A pesar de eso, y alimentadas en la crisis actual, han ganado mayores adeptos gracias a la adhesión de líderes políticos que han exaltado a su favor los ánimos de la ciudadanía, cuestionando enérgicamente la posición del enfoque de género y atemorizando a la ciudadanía al señalar que el enfoque promueve la homosexualidad, las relaciones sexuales a corta edad o que no se ha considerado la opinión de los padres de familia para su implementación.

Si bien el Perú es un país mayoritariamente católico, llama la atención los nexos que establece la Iglesia católica con los grupos económicos de poder con la intención expresa de atentar contra un enfoque que promueve la igualdad de derechos entre los ciudadanos. Al parecer, lo que se procura es aprovechar el clima de inestabilidad para impedir que toda actividad encaminada a conseguir un logro social afecte los intereses económicos de las grandes corporaciones, las cuales no pretenden ceder mayores beneficios a la población en un panorama en el cual corren el riesgo de que estos los desborden con legítimos pedidos que pongan en peligro su situación privilegiada.

\subsection{Anomia psicológica}

La crisis social actual ha ocurrido de una manera repentina, provocando una sensación de vacilación que al parecer aún ha de mantenerse. Frente al vaivén que ha significado la alteración de los diversos patrones sociales medianamente establecidos, muchas personas se han visto forzadas a cambiar los usos acostumbrados de laborar, estudiar o interactuar, de tal manera que la nueva realidad ha reconfigurado la forma en cómo los ciudadanos perciben el sistema social y también sus aspiraciones personales. No obstante, a pesar del lento proceso de adaptación, y resignación, aún se mantiene una sensación de incertidumbre respecto a los acontecimientos futuros relacionados a la propia salud, la condición laboral, las necesidades psicológicas u otras: la anomia implica justamente esta vaga percepción de que muchas pautas de conducta social han cambiado y existen otras que tampoco les generan sosiego o, en todo caso, aún no terminan por convencerlos totalmente. 
La anomia psicológica, desde su subjetividad, se manifiesta en los juicios individuales sobre la problemática social o política que se percibe. Esto ha de expresarse en los juicios sociales que elaboran los individuos, lo cual pone en evidencia sus expectativas sociales negativas, la desconfianza que le genera el Estado o el grado de descontento que experimentan (Li et al. 1999) cuando comparan, por ejemplo, su situación antes y después de la pandemia. Se mencionó que la anomia subjetiva supone una inestabilidad psicológica que la hace más propensa a la adquisición de nuevas pautas morales; de acuerdo con esto, la frase "roba, pero hace obras", muy común en la idiosincrasia peruana, hace referencia a una permisividad con los hechos de corrupción que, lamentablemente, se ha ido aceptando implícitamente por el ciudadano. Si esto no suena convincente, se podría decir que "escoger el mal menor", muy común en época electoral, también hace alusión a esta condescendencia hacia algún líder de dudosa reputación al cual finalmente la población termina adhiriéndose. El mismo caso podría aplicarse si se analiza el apoyo que recibe cualquier líder político involucrado en actos de corrupción, pero que goza momentáneamente de un respaldo masivo y emotivo del pueblo, algo muy similar a los hechos sucedidos en las marchas del mes de noviembre del año anterior. Otra frase que hace referencia a esta tolerancia es "Te falta calle" ya que, en el mismo sentido de la anterior, hace inmerecida apología a las astucia, patanería o criollismo, en desmedro de una moralidad favorable al respeto y convivencia social armoniosa. En tales casos, llama la atención la institucionalización (Parsons 1966) progresiva que han tenido este tipo de juicios y sorprende que estos no generen, por lo menos, la indignación del ciudadano sino se acepten amena, tácita e irreflexivamente.

Si bien la anomia psicológica puede analizarse desde diferentes aspectos, su efecto puede verse incluso en aquellas áreas asociadas a las necesidades psicológicas de interacción social, ocio o recreatividad. En ese contexto, la nueva realidad conlleva nuevas pautas de forzosa interacción, a causa del estado de emergencia o las cuarentenas obligatorias, a través de diversas redes o plataformas sociales como Zoom, Meet, Facebook, WhatsApp, TikTok, Instagram, entre otras, incorporadas a las rutinas laborales, académicas o sociales, las cuales han aperturado nuevos espacios y pautas de comportamiento asociados a su uso. Algunas de ellas como Tinder tienen una finalidad básica asociado a facilitar el encuentro romántico o carnal entre dos personas, y otros usos que se puede hacer de esta. No obstante, el empleo de tales redes supone el reaprendizaje de comportamientos morales asociados al tipo de informa- 
ción que se comparte, el nivel de confianza entre sus participantes y un riesgo latente de sobreexposición de información personal a la comunidad virtual. Si bien en el caso de su uso por parte de los adultos supone una capacidad reflexiva y responsabilidad, en el caso de los menores de edad la situación se torna problemática.

Esta variación cultural de las pautas acostumbradas de interacción muestra un cambio acelerado y casi obligatorio a partir del año 2020. No sería falso decir que tales transformaciones ya se han venido instalando paulatinamente, pero, a pesar de eso, aún existen ciertas reticencias o, en todo caso, aún se añora las costumbres anteriores. Nada extraño al contexto que se ha ido describiendo en los párrafos anteriores; es decir, refleja la vacilación propia ante la serie de eventos causados en el contexto de la anomia asociada a la pandemia actual.

En síntesis, la crisis estructural es percibida y ejerce una influencia en la forma en cómo los individuos construyen juicios respecto a ella: provoca un sentimiento generalizado de desconfianza hacia las instituciones sociales, frustración en sus expectativas sociales, además de generar una mayor permisividad a actos contrarios a las normas básicas de convivencia e incluso opuestos a las normas jurídicas. Adicionalmente, pone en evidencia la incertidumbre frente a las nuevas exigencias sociales en diversos ámbitos, incluidos en ellos el laboral, social o recreativo.

\section{Anomia como posibilidad de reorganización social}

En el segundo trimestre del año anterior, justo cuando los hospitales desbordaban de pacientes y se hacía notoria la falta de equipo médico para la atención, muchos empresarios ávidos de dinero comenzaron a incrementar el costo del oxígeno medicinal para el tratamiento del SARS-CoV-2; contrario a estos, un ciudadano apodado como el Ángel del Oxígeno se atrevió a mantener un precio justo y accesible a aquellas personas que necesitaban del oxígeno para la atención de sus pacientes. Poco tiempo después, este ciudadano, para el cual la justicia es más valiosa que las leyes de oferta y demanda, falleció, por esas aciagas ironías del destino, víctima del SARS-CoV-2.

En un contexto en el cual el comportamiento social procura adaptarse a la vorágine de cambios e incluso las normas morales que regulan un alza injustificada de precios lucen por su ausencia, muchos procuran sacar provecho 
a la situación o sencillamente hacer lo mismo que los demás. No obstante, el mantenerse incólume y escoger la justicia como un valor no sujeto a venta representa el heroísmo y estoicismo de este buen hombre. Este suceso, por aislado que sea, simboliza la posibilidad de reorganización social en el contexto de la crisis.

Frente a la inestabilidad de las instituciones públicas, los intereses de partidos políticos oportunistas, el egoísmo irreflexivo del sector privado y la escasa organización de una sociedad civil desacoplada que desea cambios pero no cambiar, se contrapone la capacidad de indignación del ciudadano cada vez más creciente, jóvenes y estudiantes que se han dado cuenta que deben de involucrarse en la política, los empresarios que aún tienen un sentido social genuino que va más allá del marketing de la responsabilidad social corporativa, los líderes comunitarios que se organizan para luchar contra un enemigo común como la delincuencia, los que procuran articularse con torpeza empleando desde pitos, bocinas y, ahora, alarmas, cámaras o aplicaciones sofisticadas. Sobre estas últimas se plantea la anomia como posibilidad de reingeniería social, de articular las bases de las sociedad desde sus cimientos en las asambleas comunales, de organizar sus agrupaciones de tal manera que estas tengan voz y voto político, y de tener verdaderos representantes capaces de forzar a recular a los intereses partidarios ajenos a los que persigue la sociedad civil. Si bien lejana, es esa la anomia como posibilidad de reorganización; no obstante, también puede representar otra infausta ironía, una de esas a las cuales el país lamentablemente se ha acostumbrado en su pasado.

Lejos de un llamado emotivo, la reorganización social es una labor que implica la misma dificultad que posee un cirujano que decide operarse a sí mismo; sin embargo, desde que cayó la última dictadura fujimorista a la fecha, podría decirse que la sociedad civil ha tenido mayores libertades sociales que en años anteriores. Esto ha permitido defender, con saldos fatídicos, derechos y, en algunas ocasiones, se ha logrado hacer retroceder propuestas contrarias a una gran mayoría de ciudadanos. Esto ocurre porque en los últimos años nuevas agrupaciones han aparecido y han sabido emplear las reglas de la democracia para defenderse; aunque en el actual escenario existe el riesgo continuo de volver a una época dictatorial, en la cual incluso el derecho a la vida puede estar en juego.

En esa misma línea, se espera una articulación progresiva de la sociedad civil a través de las agrupaciones comunitarias existentes, ya sea desde sus unidades básicas y los mecanismos que permiten a estas hacerse representativas. 
Por ejemplo, las asambleas comunales son organizaciones que en teoría deberían gozar de la adhesión mayoritaria de sus integrantes, ya que están orientadas a canalizar soluciones a diversas demandas. No obstante, estas tienen poca participación, a pesar de que en la década del setenta permitieron organizar distritos jóvenes como Villa El Salvador.

Si bien se asume que el sistema económico es la base estructural que guía los intereses de los ciudadanos, también existen expectativas culturales que los dinamizan. Parsons (1966) señala que los intereses del sistema de la persona son diferentes cuando estos se analizan desde un sistema de mayor jerarquía en el cual existe, por lo menos, dos actores sociales que se circunscriben implícitamente en expectativas sociales comunes y afines a esta nueva estructura. En el caso de una unidad comunitaria, como puede ser una asamblea comunal, las diferencias individuales permiten llegar a consensos y acuerdos que la benefician, a pesar de las molestias individuales que puede acarrear en sus miembros, que, si bien pueden notar un incómodo rol activo inicial, ven a mediano plazo un cambio favorable a este y a su comunidad. No obstante, la organización de tal unidad puede correr riesgo a causa de factores económicos ligados a la infraestructura, pero estos pueden superarse cuando un sistema de mayor jerarquía asume esta responsabilidad colectiva empleando recursos generados a partir de las expectativas sociales comunitarias. Estas organizaciones, como una entidad diferenciada de los actores individuales, desarrollan mecanismos basados en la interacción social que facilitan el mantenimiento de elementos infraestructurales y, sobre todo, generan un mecanismo continuo de acción social comunitaria.

Tales agrupaciones necesitan que sus demandas sean satisfechas, de lo contrario corren el riesgo de extinguirse. De acuerdo con esto, es necesario que sus lideres tengan representatividad y que estos se articulen a las diversas organizaciones como municipios, Gobiernos regionales, defensorías y otras instituciones estatales. Si bien el Estado y sus instituciones cumple un rol importante en la organización de la sociedad, dada su actual crisis y desprestigio, debe ser la sociedad civil la que llegue a este a través de líderes representativos que velen por los intereses de la mayoría y no de un grupo minoritario que utiliza las leyes o sus vacíos para generar interpretaciones favorables a sus aspiraciones económicas.

Ante la presencia de tales elementos anómalos que generan inestabilidad a nivel de las instituciones estatales, la función que asume la organización de la sociedad civil debe estar orientada a procurar el equilibrio del sistema social. 
No obstante, aún queda por resolver cómo esta hace una contraparte sólida, de tal manera que se compense las expectativas del sector privado de las grandes corporaciones, junto con el poder implícito que incluso les permite provocar inestabilidad en los sistemas estatales, y las demandas mayoritarias de los ciudadanos, los cuales deberían tener verdaderos guías políticos de sus necesidades. En ese sentido, el balance se consigue desde la representatividad de la ciudadanía a través del Estado, el cual se encargaría de proporcionar equitativamente las aspiraciones desmesuradas de las elites económicas y las demandas justas de los ciudadanos que no impliquen un populismo desenfrenado.

Frente a este cuadro, un sinfín de probabilidades aparece: anarquía, caos, el desorden social, la aparición de una nueva dictadura o un nuevo militarismo. Dentro de ellas asoma, dubitativamente, la posibilidad de borrar todo y construir de nuevo, desde sus cimientos, un país con igualdad de oportunidades en el cual fantasear con la justicia social no es una utopía ni tampoco un sueño.

\section{Conclusión}

Según el análisis realizado, la pandemia provocada por el SARS-CoV-2 ha ocasionado un escenario de inestabilidad en la estructura social del país que ya se había gestado en años anteriores. La llegada del virus extranjero solo ha tenido un efecto catalizador de las condiciones preexistentes, lo cual ha desembocado en la anomia social y la crisis observada en los sistemas sociales analizados, y a nivel de la subjetividad del individuo. Tal crisis se ha hecho evidente en las instituciones estatales como el Congreso de la República, la Presidencia, diversos ministerios, municipalidades, sector privado, sector laboral, e incluso en la psiqué del ciudadano, el cual vive en una constante incertidumbre. Adicionalmente, en el contexto de la anomia social, en un panorama afín a un apocalipsis bíblico, se postula lejanamente una posibilidad de reingeniería social a partir de la organización progresiva de la sociedad civil. 


\section{Referencias bibliográficas}

Barría, C. 2020. Coronavirus en Perú: por qué un país que tuvo un gran crecimiento económico no invirtió más en su sistema sanitario. $B B C$. https:/www.bbc.com/mundo/ noticias-52843655

Burt, J. 2011. Violencia y autoritarismo en el Perú: bajo la sombra de Sendero y la dictadura de Fujimori. Lima: Instituto de Estudios Peruanos.

Caycho, A. 2019. Propiedades psicométricas de la Escala de Anomia Social en pacientes drogodependientes peruanos. Interacciones, 5 (1), 17-23. https://doi. org/10.24016/2019.v5n1.164

Caycho, A. 2020. Estructura latente de una escala de anomia social e invarianza factorial en estudiantes peruanos de ambos sexos. Revista de Investigación en Psicología. 23 (2), 165-178. https://doi.org/10.15381/rinvp.v23i2.19239

Carrillo, J., y Sulmont, D. 1991. ¿Teoría de la anomia o anomia de la teoría? Debates en Sociologia, (16), 209-221. https://bit.ly/3kuiJog

Chirinos, R. 2008. ¿Puede el Perú ser un nuevo milagro económico? Lima: Banco Central de Reserva del Perú. https://bit.ly/2UkD0lq

Durkheim, E. 1965. El suicidio. Buenos Aires: Schapire.

Durkheim, E. 2012. La división del trabajo social. Madrid: Biblioteca Nueva.

Defensoría del Pueblo. 2020a. Reporte mensual de conflictos sociales N. ${ }^{\circ} 198$. Lima: autor. https://bit.ly/3ewAyPF

Defensoría del Pueblo. 2020b. Entrega de bonos a hogares en el contexto de la emergencia por la Covid-19: dificultades y recomendaciones. Serie Informes Especiales N. 025-2020-DP. Lima: autor. https://bit.ly/3xN1KUz

Gestión. 2020. Federación Médica anuncia huelga nacional indefinida en enero. Gestión. https://bit.ly/3B8bxnE

Li, H., Atteslander, P., Tanur, J, y Wang, Q. 1999. Anomie Scales: Measuring Social Instability. En A. Peter, B. Gransow y J. Western (Eds.). Comparative anomie research: hidden barriers-hidden potential for social development. Sídney: Ashgate.

Lynch, N. 1989. ¿Anomia de regresión o Anomia de Desarrollo?». Socialismo y Participación, (45), 39-52. http://www.acuedi.org/ddata/65.pdf

Macera, D. 2020. La pandemia informal. Instituto Peruano de Economía. https://www. ipe.org.pe/portal/la-pandemia-informal/

Merino, G. 2020. Reconfiguración del mapa del poder mundial: ascenso de Asia-Pacífico y el declive de Occidente. El País Digital. https://bit.ly/3xQoMaq

Merton, R. 1964. Teoría y estructuras sociales. Ciudad de México. Fondo de Cultura Económica 
Ministerio de Justicia y Derechos Humanos. 2019. Corrupción en el sistema de justicia: caso "los cuellos blancos del puerto. Lima: Procuradoría Pública Especializada en Delitos de Corrupción. https://bit.ly/3za6mlr

Neira, H. 1987. Violencia y anomia: reflexiones para comprender. Socialismo y Participación, (37), 1-13. https://bit.ly/2TgKpBO

Paredes, M., y Encinas, D. 2020. Perú 2019: crisis política y salida institucional. Revista de Ciencia Política, 40 (2), 483-510. Santiago de Chile. https://dx.doi.org/10.4067/ S0718-090X2020005000116

Parsons, T. 1966. El sistema social. Madrid: Biblioteca de la Revista de Occidente.

Sánchez, A. y Paredes, M. 2010. Los grandes acomodos de la derecha. Una entrevista a Francisco Durand. Quehacer, (178), 8-27. https://bit.ly/3xPO88n

Yamamoto, J. 2020. El Perú es una sociedad en un período de adolescencia rebelde (video). RPP Noticias. https://www.youtube.com/watch?v=jkOQqxHmVGc

Zapata, R. 2020. Coronavirus en regiones: investigan malos manejos en canastas familiares y escasa ejecución de fondos. Ojo Público. https://bit.ly/3zfxQWZ 